\title{
Impact of multi-vessel therapy to the risk of periprocedural myocardial injury after elective coronary intervention: exploratory study
}

\author{
Zhang-Wei Chen ${ }^{1}$, Hong-Bo Yang ${ }^{1}$, Ying-Hua Chen ${ }^{2}$, Jian-Ying Ma ${ }^{1}$, Ju-Ying Qian ${ }^{1 *}$ and Jun-Bo Ge ${ }^{1 *}$
}

\begin{abstract}
Backgrounds: Periprocedural myocardial injury (PMI) after elective percutaneous coronary intervention (PCI) significantly influences the prognosis of coronary artery disease (CAD). However, it was unclear whether the occurrence of PMI was associated with a series of controllable factors, such as PCl strategy or severity of CAD.

Methods: A total of 544 consecutive stable CAD patients underwent elective PCI were enrolled. The main outcome is PMI, defined as troponin T after PCI was at least one value above the 99th percentile upper reference limit. Major adverse cardiac events (MACE), including all-cause death, repeat myocardial infarction and target vessel revascularization were record in the period of follow-up. Univariate and multivariate analysis was applied to assess predictors for the occurrence of PMI.

Results: The incidence of PMI was 38.8\% in the study. Compared with non-PMl patients ( $n=333)$, PMI patients $(n=211)$ had more diseased vessels, higher Gensini and Syntax score. Meanwhile, there were higher incidence of MACE in PMI groups $(9.5 \%$ vs. $3.2 \%, P<0.01)$. We found that PMI patients underwent higher proportion of multi-vessel $\mathrm{PCl}$ simultaneously ( $32.2 \%$ vs. $10.5 \%, P<0.01$ ) and had more stents implanted $(1.8 \pm 0.8$ vs. $1.4 \pm 0.6, P<0.01)$. Importantly, after simultaneously adjusted by other factors (such as age, diabetes, total cholesterol, number of diseased vessels, Gensini score and stent length), the risk of PMI was still increased $84 \%$ by multi-vessel PCI independently (OR $=1.654$, $95 \% \mathrm{Cl}=1.004-2.720, P<0.05)$.

Conclusions: The phenomenon of PMl occurred more commonly in stable CAD patients underwent multi-vessel PCl. Multi-vessel international therapy could increase the risk of PMI in elective PCl.
\end{abstract}

Keywords: Coronary artery disease, Periprocedural myocardial injury, Percutaneous coronary intervention

\section{Background}

Cardiac troponin T, which is highly sensitive and specific biomarkers for myocardial injury [1], has been demonstrated to be associated with the prognosis of coronary artery disease $(\mathrm{CAD})$. Increasing studies indicate that troponin elevation after percutaneous coronary intervention (PCI), which is relatively common after elective coronary intervention [2-5], has been considered as one of predictors for cardiac prognosis in CAD patients. It

\footnotetext{
* Correspondence: Qian.juying@zs-hospital.sh.cn; Ge.junbo@hotmail.com ${ }^{1}$ Department of Cardiology, Shanghai Institute of Cardiovascular Diseases, Zhongshan Hospital, Fudan University, Shanghai 200032, People's Republic of China

Full list of author information is available at the end of the article
}

has also been demonstrated that even minor elevation in troponin $\mathrm{T}$ after elective PCI provides long-term prognostic information regarding mortality and myocardial infarction [5-8]. Therefore, it is critical for clinical practitioners to assess or find out a series of controllable factors or predictors for the occurrence of PMI, which could be useful to reduce the risk of PMI. Tandjung K found that number of implanted stents not stent type was associated with the incidence of PMI [9]. Prasad also confirmed that elevation of troponin $\mathrm{T}$ was not only associated with angiographic characteristics, but also provided long-term prognostic information [6]. However, there were few trials focused on multivariate 
analysis of the occurrence of PMI, and still fewer studies reported on the eastern population with PMI, especially in Chinese patients. Our previous study found that periprocedural myocardial injury (PMI) was associated with age, serum cholesterol and number of implanted stents [10]. Number of implanted stents was mostly determined by the severity of CAD during PCI procedure; therefore, we speculated that PMI might be partly impacted by severity of CAD or PCI strategy per se. In order to clarify this hypothesis in Chinese patients, we designed this study to demonstrate the clinical and PCIrelated risk factors of PMI, meanwhile, to clarify whether the occurrence of PMI was associated PCI strategy (such as stepwise PCI or multi-vessel PCI).

\section{Methods}

\section{Study population}

From October 2011 to June 2012, a total of 544 consecutive patients referred to our hospital with stable angina pectoris for elective PCI were enrolled. The inclusion criteria were: (1) patients with 18 to 85 years of age; (2) providing a complete clinical history; (3) underwent coronary stent implantation; (4) normal preprocedural troponin $\mathrm{T}$ (below the 99th percentile upper reference limit (URL), $<0.03 \mathrm{ng} / \mathrm{ml}[6]$ ) and creatine kinase $(\mathrm{CK})-\mathrm{MB}(<23 \mathrm{U} / \mathrm{L})$. The exclusion criteria were as follows: (1) acute coronary syndrome; (2) elevated cardiac troponin $\mathrm{T}(\geq 0.03 \mathrm{ng} / \mathrm{ml})$ and CK-MB $(\geq 23 \mathrm{U} / \mathrm{L})$ before coronary intervention; (3) heart failure, cardiomyopathy, congenital heart diseases and heart valve diseases; (4) treated coronary lesion was chronic total occlusion; (5) recent surgery or trauma; (6) active chronic inflammation; (7) dysfunction of hematological and immunological system; (8) carcinoma or a condition treated with immunosuppressive agents. We provided a written informed consent form to participants in our study and explained the entire study procedure to each patient. This study and consent procedure were approved by our local ethics committee (Ethics Committee of Zhongshan Hospital affiliated to Fudan University), and were carried out in accordance with the principles of the Declaration of Helsinki. Consent for publication of these data was obtained from each patient when they were admitted in our hospital.

\section{Clinical and laboratory measurements}

The clinical characteristics of all patients including age, gender, primary hypertension, diabetes, smoking history, hyperlipidemia were recorded. Blood pressure and heart rate admitted to hospital were also detected. Fasting blood samples before PCI were drawn to detect complete blood-cell counts and blood biochemistry.

High sensitive cardiac troponin $\mathrm{T}$ (hs-cTnT) was measured before and within $24 \mathrm{~h}$ (from 10 to $20 \mathrm{~h}$ ) after
PCI by immunoturbidimetry (Hitachi 7600-020 automatic biochemistry analyzer). The 99th percentile upper reference limit (URL) of hs-cTnT is $0.03 \mathrm{ng} / \mathrm{ml}$ (this cut-point had been used in several previous studies, such as Miller's and Prasad's studies [6, 11]). Patients with post-procedural troponin $\mathrm{T} \geq 0.03 \mathrm{ng} / \mathrm{ml}$ were defined as PMI group $(n=211)$ and others were defined as nonPMI group $(n=333)$.

\section{Echocardiography}

Echocardiography was performed in all patients using a Philips IE33 instrument (Philips, Netherlands) with a 2-3.5 $\mathrm{MHz}$ transducer (X3-1), while left ventricular ejection fraction (LVEF) were detected. Observers who detected LVEF were blinded to the results of coronary angiography and grouping.

\section{Coronary angiography and intervention strategy}

Elective coronary angiography was performed in all patients after admission. A patient was considered to have CAD when a stenosed lesion resulting in a 50\% or greater reduction in lumen diameter existed in at least one of the coronary arteries. The severity of CAD was evaluated by Gensini score and Syntax score [12, 13]. Gensini score, Syntax score, number of diseased vessels, diseased lesions, treated vessels and implanted stents were recorded by observers who were blinded to the results of laboratory testing and study grouping. Patients with Gensini scores of 20 or more were defined as having severe CAD, which was approximately equal to one stenosed lesion of $70 \%$ or more in the proximal left anterior descending artery. The characteristics of lesions were also recorded and classified according to ACC/AHA coronary lesion classification [14].

Prior to PCI, all patients received adequate loading doses of acetylsalicylic acid $(300 \mathrm{mg})$ and clopidogrel (30 $\mathrm{mg})$. The PCI procedure was performed via the femoral or radial access route. Interventional techniques and further treatment during PCI were chosen at the operators' discretion and according to current standards. Multi-vessel PCI was defined as more than one target vessel PCI at this procedure.

\section{Clinical outcomes}

The primary outcomes evaluated for the present analysis were major adverse cardiac events (MACE), which including all-cause death, fatal or nonfatal myocardial infarction (MI) and target vessel revascularization (TVR, any clinically driven repeat PCI or bypass surgery of the target vessel). The risk of target lesion revascularization (TLR) was also analyzed. 
Table 1 Comparison of clinical and laboratory characteristics between patients with and without PMI

\begin{tabular}{|c|c|c|c|}
\hline & $\begin{array}{l}\text { Non-PMl } \\
(n=333)\end{array}$ & $\begin{array}{l}\text { PMl } \\
(n=211)\end{array}$ & $P$ \\
\hline \multicolumn{4}{|l|}{ Clinical characteristics } \\
\hline Male (\%) & $231(69.4 \%)$ & $147(69.6 \%)$ & 0.941 \\
\hline Age (year) & $62.9 \pm 9.1$ & $66.4 \pm 9.3$ & $<0.01$ \\
\hline Hypertension (\%) & $215(64.6 \%)$ & $151(71.6 \%)$ & 0.090 \\
\hline Hyperlipidemia (\%) & $102(30.6 \%)$ & $71(33.6 \%)$ & 0.674 \\
\hline Diabetes (\%) & $73(22.0 \%)$ & $64(30.3 \%)$ & 0.028 \\
\hline Smoking (\%) & $140(41.4 \%)$ & $73(34.6 \%)$ & 0.088 \\
\hline LVEF (\%) & $62.4 \pm 6.7$ & $60.3 \pm 5.8$ & 0.542 \\
\hline $\begin{array}{l}\text { Systolic blood pressure } \\
(\mathrm{mmHg})\end{array}$ & $127.8 \pm 13.8$ & $133.2 \pm 15.9$ & 0.105 \\
\hline $\begin{array}{l}\text { Diastolic blood pressure } \\
(\mathrm{mmHg})\end{array}$ & $76.3 \pm 8.3$ & $75.2 \pm 8.1$ & 0.544 \\
\hline $\begin{array}{l}\text { Heart rate (beat per } \\
\text { minute) }\end{array}$ & $69 \pm 11$ & $70 \pm 8$ & 0.802 \\
\hline \multicolumn{4}{|l|}{ Laboratory characteristics } \\
\hline eGFR (ml/min) & $94.4 \pm 20.4$ & $92.6 \pm 22.6$ & 0.486 \\
\hline $\begin{array}{l}\text { Total cholesterol } \\
(\mathrm{mmol} / \mathrm{L})\end{array}$ & $3.98 \pm 1.02$ & $4.26 \pm 1.44$ & 0.018 \\
\hline Triglyceride (mmol/L) & $1.85 \pm 0.96$ & $2.04 \pm 1.89$ & 0.102 \\
\hline Pre-procedural CK-MB (U/L) & $12.4 \pm 5.8$ & $13.9 \pm 4.7$ & 0.584 \\
\hline Post-procedural CK-MB (U/L) & $18.5 \pm 10.4$ & $14.2 \pm 5.6$ & 0.054 \\
\hline $\begin{array}{l}\text { Pre-procedure troponin } \\
\mathrm{T}(\mathrm{ng} / \mathrm{ml})\end{array}$ & $0.014 \pm 0.018$ & $0.016 \pm 0.017$ & 0.872 \\
\hline $\begin{array}{l}\text { Post-procedure troponin } \\
\text { T (ng/ml) }\end{array}$ & $0.015 \pm 0.021$ & $0.156 \pm 0.291$ & $<0.01$ \\
\hline \multicolumn{4}{|l|}{ Medication before angiography } \\
\hline Beta-blocker (\%) & $273(82.0)$ & $177(83.9)$ & 0.794 \\
\hline ACEI/ARB (\%) & $229(68.8)$ & $137(64.9)$ & 0.588 \\
\hline Aspirin (\%) & 301 (90.4) & $184(87.2)$ & 0.536 \\
\hline Statin (\%) & $314(94.3)$ & $200(94.8)$ & 0.921 \\
\hline
\end{tabular}

Abbreviations: $A C E / / A R B$ s angiotensin-converting enzyme inhibitors/angiotensin receptor blocker, CK creatine kinase, eGFR estimated glomerular filtration rate, LVEF left ventricular ejection fraction, PMI Periprocedural myocardial injury

Table 2 Long-term Follow-up data of this study (median period: 18 months)

\begin{tabular}{llll}
\hline & Non-PMI $(n=271)$ & PMI $(n=170)$ & $P$ \\
\hline MACE (\%) & 9 & 16 & $<0.01$ \\
TVR (\%) & 7 & 12 & $<0.01$ \\
Repeat MI (\%) & 2 & 3 & 0.386 \\
All cause death (\%) & 0 & 1 & 0.616 \\
TLR & 5 & 9 & $<0.01$ \\
\hline
\end{tabular}

Abbreviations: MACE major adverse cardiac events, $M I$ fatal or nonfatal myocardial infarction, TLR target lesion revascularization, TVR target vessel revascularization
Table 3 Comparison of Angiography and PCl characteristics between patients with and without PMI

\begin{tabular}{|c|c|c|c|}
\hline & $\begin{array}{l}\text { Non-PMl } \\
(n=333)\end{array}$ & $\begin{array}{l}\text { PMI } \\
(n=211)\end{array}$ & P \\
\hline \multicolumn{4}{|l|}{ Angiography characteristics } \\
\hline $\begin{array}{l}\text { Number of diseased } \\
\text { vessels }\end{array}$ & $1.7 \pm 0.8$ & $2.2 \pm 0.9$ & $<0.01$ \\
\hline Multi-vessel stenosis (\%) & $166(49.8 \%)$ & 157 (74.4\%) & $<0.01$ \\
\hline $\begin{array}{l}\text { Number of diseased } \\
\text { lesions }\end{array}$ & $2.5 \pm 1.6$ & $3.6 \pm 2.0$ & $<0.01$ \\
\hline Average Gensini score & $30.6 \pm 20.0$ & $43.3 \pm 26.1$ & $<0.01$ \\
\hline Average Syntax score & $12.7 \pm 6.9$ & $16.9 \pm 9.0$ & $<0.01$ \\
\hline Severe CAD (\%) & $237(71.2 \%)$ & 194 (91.9\%) & $<0.01$ \\
\hline Target lesion characteristics & -464 lesions & -357 lesions & \\
\hline A (\%) & $86(18.5 \%)$ & $53(14.8 \%)$ & $<0.01$ \\
\hline B1 (\%) & $106(22.8 \%)$ & 64 (17.9\%) & $<0.01$ \\
\hline B2 (\%) & $110(23.7 \%)$ & $90(25.2 \%)$ & 0.048 \\
\hline C (\%) & $162(34.9 \%)$ & $150(42.0 \%)$ & $<0.01$ \\
\hline \multicolumn{4}{|l|}{$\mathrm{PCl}$ characteristics } \\
\hline Number of target vessels & $1.1 \pm 0.4$ & $1.3 \pm 0.5$ & $<0.01$ \\
\hline Multi-vessel PCI (\%) & $35(10.5 \%)$ & $68(32.2 \%)$ & $<0.01$ \\
\hline $\begin{array}{l}\text { Number of implanted } \\
\text { stents }\end{array}$ & $1.4 \pm 0.6$ & $1.8 \pm 0.8$ & $<0.01$ \\
\hline Total stent length (mm) & $34.7 \pm 17.8$ & $49.4 \pm 25.9$ & $<0.01$ \\
\hline \multicolumn{4}{|l|}{ Type of stents } \\
\hline -Sirolimus stent (\%) & $166(49.8)$ & $98(46.4)$ & 0.224 \\
\hline -Everolimus stent (\%) & $134(40.2)$ & $84(40.0)$ & 0.842 \\
\hline -Others (\%) & $33(10.0)$ & $29(13.6)$ & 0.218 \\
\hline $\begin{array}{l}\text { Max inflation pressure } \\
\text { (atm) }\end{array}$ & $13.3 \pm 2.6$ & $13.0 \pm 1.7$ & 0.762 \\
\hline Contrast volume (ml) & $144.8 \pm 47.3$ & $172.3 \pm 63.5$ & $<0.01$ \\
\hline \multicolumn{4}{|l|}{ Procedural complications } \\
\hline No reflow/slow reflow & $4(1.2 \%)$ & $2(1.0 \%)$ & 0.682 \\
\hline Side-branch occlusion (\%) & $10(3.0 \%)$ & $12(5.7 \%)$ & 0.064 \\
\hline Distal thrombosis & $1(0.3 \%)$ & $1(0.5 \%)$ & 0.342 \\
\hline
\end{tabular}

Abbreviations: $P C I$ Percutaneous coronary intervention, $P M I$ Periprocedura myocardial injury

\section{Statistical Analysis}

All statistical analyses were performed with SPSS software 19.0. Data were presented as the percentage or mean \pm standard deviation (SD). Chi-square analysis was used to compare the frequency for categorical variables, and Student's $t$ or correction $t$ tests were used to compare means for continuous variables. Correlation analysis (Spearman test) was performed to evaluate the correlations among serum level of post-procedural troponin T, Gensini score and stent length. Multivariable analysis (logistic) was performed to identify the independent risk factors for PMI, to clarify whether the 


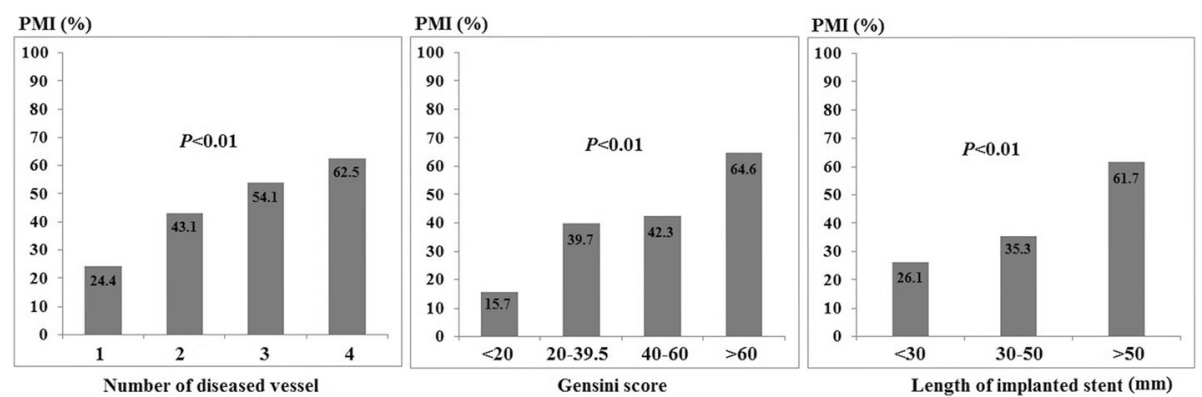

Fig. 1 Incidence of PMl in patients stratified by severity of CAD

occurrence of PMI was associated PCI strategy (such as stepwise PCI or multi-vessel PCI). All $P$-values were two-sided, and $P<0.05$ was considered to indicate statistical significance.

\section{Results}

Population baseline characteristics and clinical outcomes A total of 544 stable CAD patients underwent elective PCI were enrolled in this study from October 2011 to June 2012. There were 378 men (69.5\%) and 166 women (30.5\%). The prevalence of hypertension, diabetes, and hyperlipidemia were $67.2 \%$ (366 patients), $25.2 \%$ (137 patients) and $31.8 \%$ (173 patients), respectively. Elevation of post-procedural troponin $\mathrm{T}$ observed in 211 patients (38.8\%) (Average troponin $\mathrm{T}$ level: $0.156 \pm$ $0.291 \mathrm{ng} / \mathrm{ml}$ ) were defined as PMI group. Patients with normal post-procedural troponin $\mathrm{T}$ were defined as non-PMI group $(n=333$, average troponin T: $0.015 \pm$ $0.021 \mathrm{ng} / \mathrm{ml}$ ). Baseline clinical characteristics of these patients were shown in Table 1 .

The median period of follow-up in our study was 18.5 months. During the period of follow-up, 441 patients $(81.0 \%)$ completed the clinical follow-up. The outcome of MACE was significantly higher in PMI group than that in non-PMI group $(9.5 \%$ vs. $3.2 \%, P<0.01)$. We also found that the incidence of TLR was higher in PMI groups $(5.4 \%$ vs. $1.7 \%, P<0.01)$ (Table 2$)$.

\section{Angiographic and procedural characteristics}

There were 1032 diseased vessel in these 544 patients. A total of 653 target vessels (1.2 target vessel per patient) were implanted with drug-eluting stent (DES). Angiographic characteristics were described in Table 3. Compare with non-PMI patients, PMI patient suffered from more severe CAD with higher Gensini score $(43.3 \pm 26.1$ vs. $30.6 \pm 20.0 ; P<0.01)$, higher Syntax score $(12.7 \pm 6.9$ vs. $16.9 \pm 9.0, P<0.01)$, more diseased vessels $(2.2 \pm 0.9$ vs. $1.7 \pm 0.8 ; P<0.01)$ and more diseased lesions $(3.6 \pm 2.0$ vs. $2.5 \pm 1.6 ; P<0.01)$. They also had more type $C$ lesions than those in non-PMI group (Table 3 ).

As concern to PCI characteristics (shown in Table 2), we found that PMI patients had higher proportion of multi-vessel PCI $(32.2 \%$ vs. $10.5 \%, P<0.01)$, more implanted stents $(1.8 \pm 0.8$ vs. $1.4 \pm 0.6, P<0.01)$ and longer total length of implanted stents $(49.4 \pm 25.9$ vs. $34.7 \pm 17.8, P<0.01)$.

\section{PMI associated with severity of CAD}

In order to clarify the association between occurrence of PMI and the severity of CAD, subgroups analysis was also performed in our study (Fig. 1). After stratified by the number of diseased vessels, extent of Gensini score and total length of implanted stents, we found that the incidence of PMI was significantly increased in more severe CAD patients.

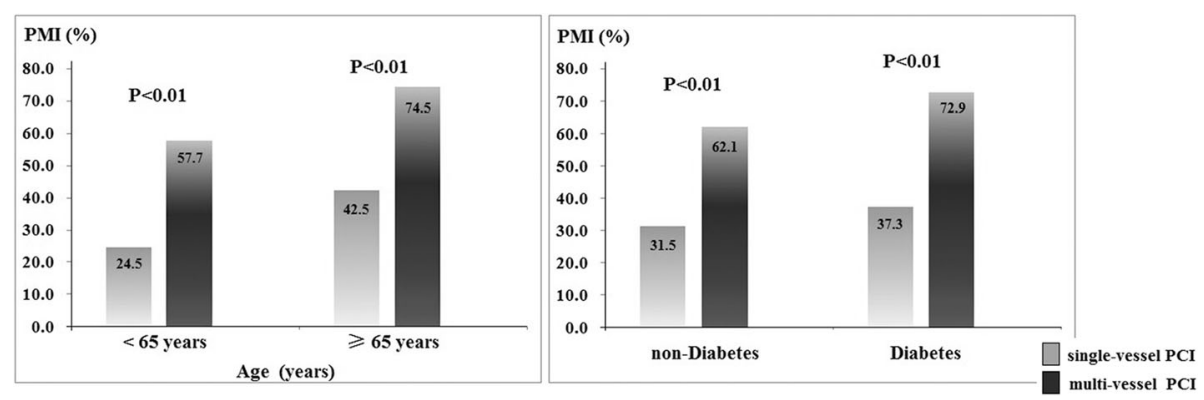

Fig. 2 Incidence of PMI in multi-vessel and single-vessel PCl patients stratified by age and diabetes 

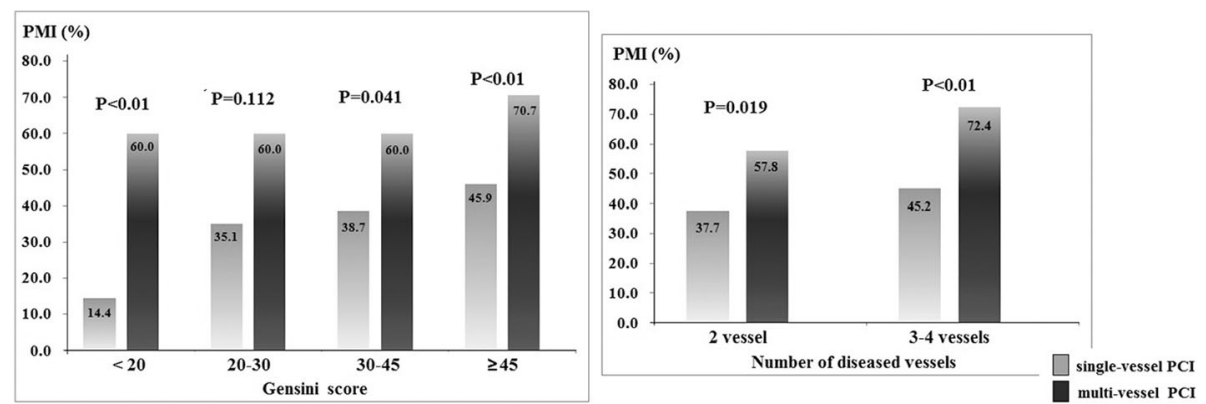

Fig. 3 Incidence of PMI in multi-vessel and single-vessel PCI patients stratified by severity of disease

\section{Effect of Multi-vessel PCI on PMI}

In this study, we found that patients with multi-vessel PCI simultaneously underwent higher proportion of PMI than those in single-vessel PCI group $(66.0 \%$ vs. $32.8 \%, P<0.01)$. In order to clarify the independent effect of multi-vessel PCI on PMI, we re-analyzed the effect of multi-vessel PCI after stratified patients by other factors, such as age, diabetes, Gensini score, number of diseased vessel, number of stents and total stent length. Multi-vessel PCI significantly increased the incidence of PMI in each sub-group analysis (Figs. 2, 3 and 4). Stratified by number of diseased vessel, patients with multi-vessel PCI had higher risk of PMI (2-vessel group: $57.8 \%$ vs. $37.7 \%$; $3-4$ vessel group: $72.4 \%$ vs. $45.2 \%, P<$ 0.01). While stratified by similar length of stents, patients with multi-vessel PCI also had higher prevalence of PMI (<30 mm stent length: $57.1 \%$ vs. $24.9 \%$; 30-50 mm stent length: $56.0 \%$ vs. $32.8 \%$; $>50 \mathrm{~mm}$ stent length: $70.4 \%$ vs. $54.1 \%, P<0.05)$.

Meanwhile, univariate analysis and multivariate logistic analysis were used to evaluate independent effect of multi-vessel PCI on the risk of PMI. In this analysis, PMI was adjusted by age, diabetes, cholesterol, number of diseased vessels, Gensini score, number of implanted stents and stents length. No matter adjusted by single factor or together, the risk of PMI was increased independently by multi-vessel PCI $(\mathrm{OR}=1.654,95 \%$ $\mathrm{CI}=1.004-2.720, P<0.05$ ) (Tables 4 and 5 ).

\section{Discussion}

As we know, PCI significantly improved the symptoms and prognosis in CAD patients. However, PMI, which occurred approximately $30 \%$ of patients after elective PCI, has been one of critical problems $[15,16]$. Several previous studies documented that there was a significant association between cardiac adverse prognosis and PMI $[6-8,17,18]$. Therefore, another important thing is to find out why and when PMI happens or what its risk factors are.

Many prospective studies found that PMI patients always combined with more severe coronary disease, higher serum lipid level and more common clinical complications $[6,10]$. Prasad also reported that postprocedural elevation of cardiac troponin was associated with multi-vessel PCI. However, there was few multivariate analysis applied between occurrence of PMI and its risk factors. Multi-vessel disease must be associated with severity of CAD, which could be demonstrated by severity score. Therefore, in order to eliminate the confounding impact of disease severity and stent length (which was related to PCI approach), multivariate logistic analysis was applied. As we showed in Table 4, not only patient-oriented factors, but also severity score, stents' length and multi-vessel PCI approach were adjusted by logistic analysis together. We found that even adjusted by disease severity and stent length, multi-vessel PCI still increase the risk of PMI independently. In previous

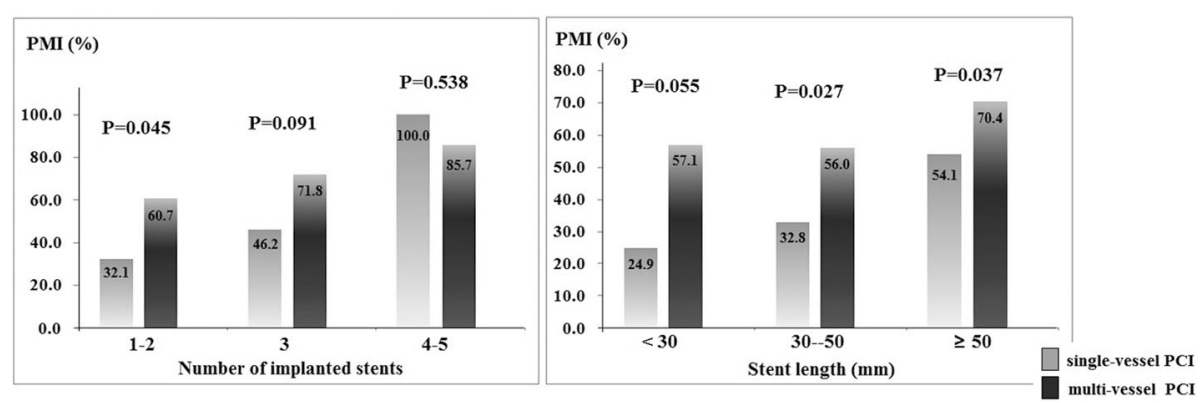

Fig. 4 Incidence of PMI in multi-vessel and single-vessel PCl patients stratified by stent length and number 
Table 4 Odds ratios of patient-oriented and PCl-oriented factors for PMI (univariate analysis)

\begin{tabular}{|c|c|c|c|}
\hline Adjusted by & OR & $\begin{array}{l}95 \% \text { confidence } \\
\text { intervals }\end{array}$ & $P$ \\
\hline \multicolumn{4}{|l|}{ Patient-oriented factors } \\
\hline Age & 1.043 & $1.023-1.063$ & $<0.01$ \\
\hline male & 1.014 & $0.697-1.475$ & 0.941 \\
\hline Diabetes & 1.551 & $1.048-2.295$ & 0.028 \\
\hline Hypertension & 1.381 & $0.950-2.008$ & 0.091 \\
\hline Total cholesterol & 1.322 & $1.022-1.711$ & 0.018 \\
\hline Triglyceride & 1.150 & $0.940-1.408$ & 0.102 \\
\hline \multicolumn{4}{|l|}{$\mathrm{PCl}$-oriented factors } \\
\hline Gensini score & 1.026 & $1.017-1.034$ & $<0.01$ \\
\hline $\begin{array}{l}\text { Number of diseased } \\
\text { vessels }\end{array}$ & 1.867 & $1.516-2.298$ & $<0.01$ \\
\hline $\begin{array}{l}\text { Number of implanted } \\
\text { stents }\end{array}$ & 2.329 & $1.805-3.005$ & $<0.01$ \\
\hline Total stent length & 1.032 & $1.023-1.041$ & $<0.01$ \\
\hline Multi-vessel PCl & 4.092 & $2.588-6.469$ & $<0.01$ \\
\hline
\end{tabular}

Abbreviations: $P C I$ Percutaneous coronary intervention, $P M I$ Periprocedural myocardial injury

studies [6], there was also significant difference of multivessel PCI rate between PMI and non-PMI groups; however, it was only presented by univariate analysis. As we know, multi-vessel PCI was not only determined by multi-vessel disease and severe stenosis in each vessel, but also presented as different numbers of stents and different lengths of stents implantation. Therefore, multivariate analysis was performed in our study, while severity of CAD, numbers of stents and length of implanted stents were controlled simultaneously.

In this study, Gensini score, Syntax score, number of diseased vessel and number of implanted stents were applied to evaluate the severity of CAD. We found that occurrence of PMI was increased significantly in more

Table 5 Odds ratios of multivessel PCI for PMI adjusted by several factors (multivariate logistic analysis)

\begin{tabular}{llll}
\hline Adjusted by & OR & $\begin{array}{l}\text { 95\% confidence } \\
\text { intervals }\end{array}$ & $P$ \\
\hline Multi-vessel PCI (not adjusted) & 4.092 & $2.588-6.469$ & $<0.01$ \\
Age & 4.224 & $2.649-6.734$ & $<0.01$ \\
Diabetes & 3.965 & $2.503-6.282$ & $<0.01$ \\
Total cholesterol & 3.136 & $1.829-5.629$ & $<0.01$ \\
Gensini score & 2.809 & $1.717-4.595$ & $<0.01$ \\
Number of diseased vessels & 2.750 & $1.667-4.537$ & $<0.01$ \\
Number of implanted stents & 2.167 & $1.249-3.758$ & $<0.01$ \\
Total stent length & 2.323 & $1.330-3.745$ & $<0.01$ \\
Adjusted by all these factors & 1.654 & $1.004-2.720$ & 0.045 \\
\hline Abbreviations: PCl Percutane &
\end{tabular}

Abbreviations: $P C I$ Percutaneous coronary intervention, $P M I$ Periprocedural myocardial injury severe CAD patients (Fig. 1). It has been documented that the most common mechanisms for PMI are distal embolization or side branch occlusion [16, 19]. Vessel lumen enlargement after stenting implantation probably results in a combination of plaque compression, plaque extrusion, plaque redistribution and micro-vessel embolization [20]. Severe stenosed lesions, with large lipid or necrotic core plaque, are at high risk of microembolization during the procedure of lesion enlargement and stents implantation [21]. Therefore, it is inevitable for PCI to result in different extent of microembolization. Post-procedural troponin $\mathrm{T}$ elevation may be a marker for severe atherosclerosis, increased plaque burden [22], presence of vulnerable plaques, endothelial dysfunction, microvascular injury, and inflammation [23].

Besides the severity of CAD, detailed PCI procedure was also compared between PMI and non-PMI groups. As we know, even among patients with the same number of PCI vessels, they still presented as different number and total length of implanted stents. Therefore, the association between multi-vessel PCI and higher prevalence of PMI might be confounded by number of stents and length of stents. In order to clarify the independent effect of multi-vessel PCI on PMI occurrence, we re-evaluated the effect of multi-vessel PCI in subgroup and multivariable analyses. When patients were stratified by number of implanted stents and stents length, incidence of PMI was increased significantly in multi-vessel PCI group. Most importantly, after analyzed by multivariate analysis, multi-vessel PCI was independently increased the risk of PMI.

We should note some of our study's limitations. First, the number of included patients was small size. Second, it was a retrospective study, and its retrospective and non-randomized nature limited its potency to clarify the association between PMI and follow-up data. Third, present study did not include routine intravascular ultrasound, which was quite accuracy for lesion characteristic evaluation. These limitations will be taken into account in our further clinical researches and prospective studies.

\section{Conclusions}

The phenomenon of PMI occurred more commonly in stable CAD patients underwent multi-vessel PCI. Multivessel international therapy could increase the risk of PMI in elective PCI.

\section{Abbreviations}

ACEI/ARBs: Angiotensin-converting enzyme inhibitors/angiotensin receptor blocker; CAD: Coronary artery disease; CK: Creatine kinase; eGFR: Estimated glomerular filtration rate; LVEF: Left ventricular ejection fraction; MACE: Major adverse cardiac events; MI: Myocardial infarction; OR: Odds ratio; PCI: Percutaneous coronary intervention; PMl: Periprocedural myocardial injury; TLR: Target lesion revascularization; TVR: Target vessel revascularization 


\section{Acknowledgements}

Not applicable.

\section{Funding}

This study was supported by the National Natural Science Foundation of China (Grant No: 81570314, 81200146 and 81370322), Grant of Zhongshan hospital (Grant No: 2015ZSYXGG07 and 2012ZSQN12), New Teacher Foundation of Ministry of Education (Grant No: 20120071120061$)$, Grant of Shanghai Municipal Science and Technology Commission (Grant No: 15XD1501 100), Grant of Shanghai municipal commission of health and family planning (Grant No: XBR2013071, 20134001 and 20144Y0240) and Grant of Shanghai Pudong New District of health and family planning (Grant No: PW2014A-13).

\section{Availability of data and materials}

All data generated or analysed during this study are included in this published article. The datasets used and analyzed during the current study are available from the corresponding author on reasonable request.

\section{Authors' contributions}

Chen ZW participated in conception and design, acquisition of data and drafting the manuscript. Yang HB carried out the acquisition of data and further analysis. Chen YH carried out the acquisition of data. Ma JY interpreted and analyzed the data. Qian JY took part in study design. Ge JB participated in study design and helped to draft the manuscript. All authors read and approved the final manuscript.

\section{Competing interests}

There are no conflicts of interest pertained to this submission.

\section{Consent for publication}

Not applicable.

\section{Ethics approval and consent to participate}

This study and consent procedure were approved by our local ethics committee (Ethics Committee of Zhongshan Hospital affiliated to Fudan University), and were carried out in accordance with the principles of the Declaration of Helsinki. Consent for publication of these data was obtained from each patient when they were admitted in our hospital.

\section{Author details}

'Department of Cardiology, Shanghai Institute of Cardiovascular Diseases, Zhongshan Hospital, Fudan University, Shanghai 200032, People's Republic of China. ${ }^{2}$ Department of Endocrinology, East Hospital, Tongji University, Shanghai 200120, People's Republic of China.

Received: 23 January 2016 Accepted: 14 February 2017 Published online: 27 February 2017

\section{References}

1. Thygesen K, Alpert JS, Jaffe AS, et al. Third universal definition of myocardial infarction. Eur Heart J. 2012:33:2551-67.

2. Ravkilde J, Nissen H, Mickley H, Andersen PE, Thayssen P, Hørder M. Cardiac troponin $T$ and $C K-M B$ mass release after visually successful percutaneous transluminal coronary angioplasty in stable angina pectoris. Am Heart J. 1994;127:13-20.

3. Johansen O, Brekke M, Strømme JH, et al. Myocardial damage during percutaneous transluminal coronary angioplasty as evidenced by troponin T measurements. Eur Heart J. 1998;19:112-7.

4. Cantor WJ, Newby LK, Christenson RH, et al. Prognostic significance of elevated troponin I after percutaneous coronary intervention. J Am Coll Cardiol. 2002;39:1738-44

5. Jeremias A, Kleiman NS, Nassif D, et al. Prevalence and prognostic significance of preprocedural cardiac troponin elevation among patients with stable coronary artery disease undergoing percutaneous coronary intervention: results from the evaluation of drug eluting stents and ischemic events registry. Circulation. 2008:118:632-8.

6. Prasad A, Singh M, Lerman A, Lennon RJ, Holmes Jr DR, Rihal CS. Isolated elevation in troponin T after percutaneous coronary intervention is associated with higher long-term mortality. J Am Coll Cardiol. 2006;48:1765-70.
7. Cuculi F, Lim CC, Banning AP. Periprocedural myocardial injury during elective percutaneous coronary intervention: is it important and how can it be prevented? Heart. 2010;96:736-40.

8. Vranckx P, Farooq V, Garg S, et al. Different cardiac biomarkers to detect peri-procedural myocardial infarction in contemporary coronary stent trials: impact on outcome reporting. Heart. 2012;98:1424-30.

9. Tandjung K, Basalus MW, Muurman E, et al. Incidence of periprocedural myocardial infarction following stent implantation: comparison between first- and second-generation drug-eluting stents. Catheter Cardiovasc Interv. 2012;80:524-30.

10. Chen ZW, Qian JY, Ma JY, Ge L, Ge JB. Risk factors of cardiac troponin T elevation in patients with stable coronary artery disease after elective coronary drug-eluting stent implantation. Clin Cardiol. 2011;34:768-73.

11. Miller WL, Garratt KN, Burritt MF, Lennon RJ, Reeder GS, Jaffe AS. Baseline troponin level: key to understanding the importance of post-PCI troponin elevations. Eur Heart J. 2006;27:1061-9.

12. Gensini GG. A more meaningful scoring system for determining the severity of coronary heart disease. Am J Cardiol. 1983;51:606.

13. Girasis C, Garg S, Räber L, et al. SYNTAX score and Clinical SYNTAX score as predictors of very long-term clinical outcomes in patients undergoing percutaneous coronary interventions: a substudy of SIRolimus-eluting stent compared with pacliTAXel-eluting stent for coronary revascularization (SIRTAX) trial. Eur Heart J. 2011;32:3115-27.

14. Ellis SG, Vandormael MG, Cowley MJ, Disciascio G, Deligonul U, Topol EJ, Bulle TM. Coronary morphologic and clinical determinants of procedural outcome with angioplasty for multivessel coronary disease. Implications for patient selection. Multivessel Angioplasty Prognosis Study Group. Circulation. 1990;82:1193-202.

15. Prasad A, Herrmann J. Myocardial infarction due to percutaneous coronary intervention. N Engl J Med. 2011;364:453-64.

16. Babu GG, Walker JM, Yellon DM, Hausenloy DJ. Peri-procedural myocardial injury during percutaneous coronary intervention: an important target for cardioprotection. Eur Heart J. 2011;32:23-31.

17. Nienhuis MB, Ottervanger JP, Bilo HJ, Dikkeschei BD, Zijlstra F. Prognostic value of troponin after elective percutaneous coronary intervention: a metaanalysis. Catheter Cardiovasc Interv. 2008;71:318-24.

18. Testa L, Van Gaal WJ, Biondi Zoccai GG, et al. Myocardial infarction after percutaneous coronary intervention: a meta-analysis of troponin elevation applying the new universal definition. QJM. 2009;102:369-78.

19. Brener SJ, Ellis SG, Schneider J, Topol EJ. Frequency and long-term impact of myonecrosis after coronary stenting. Eur Heart J. 2002;23:869-76.

20. Ahmed JM, Mintz GS, Weissman NJ, et al. Mechanism of lumen enlargement during intracoronary stent implantation: an intravascular ultrasound study. Circulation. 2000;102:7-10.

21. Kawamoto T, Okura H, Koyama Y, et al. The relationship between coronary plaque characteristics and small embolic particles during coronary stent implantation. J Am Coll Cardiol. 2007;50:1635-40.

22. Mehran R, Dangas G, Mintz GS, et al. Atherosclerotic plaque burden and CK$\mathrm{MB}$ enzyme elevation after coronary interventions: intravascular ultrasound study of 2256 patients. Circulation. 2000;101:604-10.

23. Ellis SG, Chew D, Chan A, Whitlow PL, Schneider JP, Topol EJ. Death following creatine kinase-MB elevation after coronary intervention: identification of an early risk period: importance of creatine kinase-MB level, completeness of revascularization, ventricular function, and probable benefit of statin therapy. Circulation. 2002;106:1205-10.

\section{Submit your next manuscript to BioMed Central and we will help you at every step:}

- We accept pre-submission inquiries

- Our selector tool helps you to find the most relevant journal

- We provide round the clock customer support

- Convenient online submission

- Thorough peer review

- Inclusion in PubMed and all major indexing services

- Maximum visibility for your research

Submit your manuscript at www.biomedcentral.com/submit
) Biomed Central 